Humanist Studies \& the Digital Age, 4.1 (2015)

ISSN: 2158-3846 (online)

http://journals.oregondigital.org/hsda/

DOI: 10.5399/uo/hsda.4.1.3685

(cc) BY-ND

\title{
Circles: Networks of Reading
}

\author{
Massimo Lollini, University of Oregon
}

Tell all the truth but tell it slant / Success in Circuit lies / Too bright for our infirm Delight / The Truth's superb surprise.

Emily Dickinson, 506.

Reading is a neuronally and intellectually circuitous act, enriched as much by the unpredictable indirections of the reader's inferences and thoughts, as by the direct message to the eye from the texts.

Wolf, Proust and the Squid 16

Welcome to the fourth issue of Humanist Studies \& the Digital Age. It continues the discourse started in the third issue, "Textualities in the Digital Age"; this time we focus on the role of the reader in digital environments. An analysis of current digital projects follows the historical and theoretical premise.

As Marianne Wolf remind us in her book deeply rooted in neuroscientific knowledge, "we were never born to read. Human beings invented reading only a few thousand years ago" (Proust and the Squid, 3). This was one of the most extraordinary inventions in human history, responsible for altering the organization of human brain and the intellectual evolution of our species. Reading is based on multiple cognitive processes, the most ancient of which were the visual areas in our ancestors' brain that were responsible for object recognition. Then the brain learned to make connections, circuits, and pathways between the visual areas and those responsible for linguistic processes, essential for the development of written language (14). This means our brain has to connect to older structures of vision and language to learn to read. While some of the cognitive processes involved in reading, like vision and speech, are genetically organized, reading in itself does not have "direct genetic program passing it to future generations" (11). This makes reading an activity particularly sensitive to each new type of writing system developed through the millennia of human history, causing different adaptations to the human brain. For the same reason, if we want to understand the actual condition and the future of reading it is important to understand the evolution of reading and writing systems through the centuries. To do so we need to adjourn, and for certain aspects suspend, the modern notions of author and book which have been considered crucial for both the writer and the reader since the age of printing. Rather than limiting our attention to books and authors, we need to understand the evolution of the textualities involved in writing and reading and their circumstances. 
The idea that authors do not write books but texts incarnated in different written objects including manuscripts, printed books, and electronic texts is becoming more and more familiar in our digital time. The familiarity with manuscripts and incunabula has long ago lead scholars to point out the necessity of distinguishing between physical materials and their supporting structure, such as the book, that are unique and singular and the "abstraction" that we refer to under the name "text," which is ideal and reproducible. As Joseph Dane writes in his The Myth of Print Culture, "In the earliest printed books we have ... there is not a single question in bibliographical or literary history that could not be considered a variant" (Dane 9). For this reason we should be concerned above all with texts but at the same time take into the appropriate consideration their supporting structure as well. Guglielmo Cavallo and Roger Chartier in their Introduction to $A$ History of Reading in the West emphasize that "reading is not already inscribed in the text" (1); the "meanings of texts depend on the forms and circumstances through which they are received and appropriated by their readers" (2). In other words, the crucial role of the reader in giving texts a meaning depends on the forms of writing and supporting structure through which the text is transmitted. Cavallo and Chartier go so far as to say that forms produce meaning and every change in support produces new meaning. Therefore, the history of reading has to consider both the physical aspects of text and their readers practices, usually organized around what Stanley Fish calls "interpretative communities" (Fish 147-174).

\section{The reader from volumen to codex}

The first revolution in reading in early modernity is not related to the technological revolution in book production, but to the change in writing practices that took place in the twelfth and thirteenth centuries. At that time the monastic model of writing and reading, which was related above all to a direct use in the monastery in the daily prayers read aloud, was progressively supplanted by the Scholastic model of writing and reading that attributes a new value to the book as a tool for intellectual reflection and labor. Illich has rightly emphasized a distinct correspondence between the newly laid-out page and the new setting for reading within the nascent universities that replaced monastic rituals with academic ones based on thought-through arguments (Cavallo, Chartier 24; Ilich 25, 65, 99). These changes are related to the idea that writing is not related only to Latin and lectio divina but can be used also to transcribe vernacular literature. From a technological point of view, this revolution follows from the new status of the page in the transformation of the support of writing and reading from the continuous volumen to the codex. Before the transformation of the volumen in papyrus read horizontally (fig. 1-2) into the codex in the Middle Ages, the creation of the rotulus in parchment started a reading process perpendicular to the direction of the scroll (fig. 3).

The page does not have autonomy of either the volumen or the rotulus. It remains confused with its support structure as an expression of intellectual rumination and temporal continuity. While the use of paper in place of parchment accompanied the emergence of vernacular literatures, the technological revolution of alphabetic writing and reading was enhanced and reinforced above all by the logic and structural organization of the codex as the earliest form of the book. The sacred dimension of the 
divine lectio described for example by Hugh of Saint Victor's Didascalicon, a work written in the first half of the twelfth century, was lost along with the monastic practice of group and vocal reading. Hugh wrote his Didascalicon de studio legendi to join the monks in praise of the richness and fruitfulness of this practice just as it was being eclipsed by the new technology of the book and the new practice of scholastic reading as a predominantly silent activity performed by individuals.

Cavallo and Chartier have underlined the fundamental importance of the change from a ritualized and oralized reading to silent and reflective reading that was first made possible by the appearance of word separation in the lines of early medieval manuscripts (24). This change preceded the revolution of the codex and started the process of "disincarnating of the page" that will be taken to extremes by a book technology that progressively eliminated glosses, commentaries and any form of marginal text from the page. In the codex, the page ceased to be a continuous row of columns, a simple support of memory, providing the rhythm of the oral and public reading. Instead, it became an independent visual entity with a rectangular format that is separate and discontinuous (Zali 36-37). Hugh still considered reading a physical activity, one in which all the body and the senses are involved. Reading for him meant literally to embody the pages and the letters, triggering a fertility of sensory drives that would disappear in modern European languages and printed books (Hugh of Saint Victor III 1-12; Illich 54). "Page" in Latin meant originally "vineyard"; hence the idea of reading as "harvesting grapes," a motor and sensory activity related to spiritual elevation. In its Mediterranean etymology before becoming the page in black and white that we know from the printing age on, the page was first of all pagina mundi, page-landscape, geographical space delimiting the cultivation area. The arbitrary limits of the page distinguished the natural surface from the space of writing, as "symbolic space of exchange" (Illich 57; Zali 26-27).

The illuminated manuscript was like a medieval cathedral with all its colors and decorations. These elements progressively disappear in the page of the codex and new book format following the new indexing elements that created an abstract, bi-dimensional and disembodied space for reading. The visible page ceased to be the record of speech and a series of commentaries freely available to the reader. Instead it became a space laid out by an author responsible for choosing the subject and the ordinatio. Yet, as Franco Alessio has suggested, models of knowledge in the Middle Ages did not suppose the text to be intangible. In fact, the medieval Scholastic method is based on the manipulation of texts. This happens in different ways as described by a famous quote from Saint Bonaventure's Commentarium in I Librum Sententiarum written in the thirteen century that explains the different meanings of book writing at that time. On the one hand, the copyist (scriptor) just transcribes the text of another without introducing changes; on the other hand, the compiler (compilator) cuts and pastes sections of texts of others giving them a logic order. Furthermore, according to Bonaventure, the commentator (commentator), who reproduces essential excerpts of texts of others and adds comments on how to interpret them, represents a third example of book writing. Finally, the author (auctor) creates new texts employing the texts of others only inasmuch as they confirm the authorial discourse. The prevalent dimension of these reading and writing practices as conceived by the Scholastic method is based on disarticulating the texts of others and 
interposing them with different citations that are re-ordered, glossed and commentated, mainly for studying and/or preservation purposes. Against this, the Benedectine monastic mode of reading was not aimed at preserving or understanding texts, but at preparing them for the use in monastic life and in this perspective was more inclined to preserve the texts in their integrity (Buonaventure 14-15; Alessio 102-103).

The Scholastic mode of reading is based on the lectio, performed to understand a text and ultimately to teach and learn. Reading is here strictly connected to writing and performed in three basic stages. First comes the comprehension of the literal meaning of the text (littera) related to its grammatical structure; it corresponds to the exposition (expositio) of the text. Whereas the monastic reading, not concerned with intellectual inquiry but with praying and contemplating, would stop here, Scholastic reading considers the littera only the first step of the process of reading meant to approach the more complex layers of meaning of the text. Thus, the second stage of reading in the Scholastic method is represented by the attention to the meaning (sensus), which is more or less the plain explanation (explicatio) of the literal meaning of the text. Finally, the last stage is meant to extract the essential core of the text, its doctrine or teaching (sententia). The sententia is the fundamental goal of reading in Scholastic method; it will become the object of the preservation and transmission of knowledge in the nascent universities.

Interlinear glosses on the littera and the sensus, and marginal glosses and commentaries on the sententia are also important elements of the Scholastic method. The auctoritas of the text is not related to its author but to the teachings that the reader is able to extract from it (Alessio 109, 117). In this perspective, the Scholastic method proceeds with quaestiones interrogating and challenging the texts and aims at collecting sententiae in summae and complilationes. Ultimately, the compilationes emerge in the twelfth-century universities as an open textual form not based on an authorial voice; they are the result of the reader's intervention into the texts. The medieval and Scholastic way of writing, reading, and transmitting texts and cultural heritages represents a crucial achievement in the intellectual history of reading and for certain aspects an interesting and inspiring model for the second and third revolution in reading.

\section{The reader in the network of printing and the places of reading}

The second "revolution in reading" of the early modern age arrived with the industrialization of printing. Cavallo and Chartier have questioned the traditional idea that this change corresponded to the evolution from an "intensive" to an "extensive" reading because extensive readers existed already before the printing revolution and intensive readers continued to exist after that (24-25). A good example of extensive reading that precedes the technological changes introduced by printing is the book wheel created by early humanists and perfected during the Renaissance. One good exemplary was built in the second half of sixteenth century by Italian engineer Agostino Ramelli (1531-ca.1600). The wheel of books is one of the many fantastic designs by Ramelli, published in his Diverse et artificiali Machine (Paris, 1588); it consists of a rotating lectern, designed to allow easy simultaneous reading of several texts. This rotating lectern allowed the provision of more books, and the passage from one to another by pressing a 
foot pedal. In many ways, it is a mechanism that seems to anticipate the reading of hypertexts that was conceived centuries later during the third "revolution in reading" introduced by computer technology. La ruota dei libri by Agostino Ramelli illustrates very well the humanist way of reading, based on the collation of different texts and the consultation of several book at once. A technique of reading that constituted the foundation of the fundamental humanist activity: philology. See fig. 4.

The commonplace book is another object that incarnated the model of humanist extensive reading before the printing age; it was based on collecting, comparing, ordering, and collating many different texts. Giovanni Boccaccio's Zibaldone Laurenziano XXIX 8 can be considered an early example; it is a miscellaneous work that includes Latin and vernacular authors and points to how widely read Boccaccio was. ${ }^{1}$ The zibaldone (or hodgepodge book) became a new form of book production in the fifteenth century in Italy. These commonplace books were written in cursive scripts and contained an overwhelming variety of poetic and prose texts: literary texts, mostly of the three major figures of the Florentine vernacular traditions, appeared side-by-side in no discernible order with lists of taxes paid, currency exchange rates, devotional texts, favorite quotes from Virgil and Augustine. ${ }^{2}$ Commonplace books represent an important source for studying the emergence of a lay literature and interpreting merchants' and artisans' interaction with literary texts and visual arts during the Renaissance (Petrucci, Writers and Readers in Medieval Italy 185). Figure $\mathbf{5}$ is taken from an early example of a merchant's commonplace book, a manuscript on paper written in Italian and Latin with extracts in Venetian, dating between 1350-1400. The book contains notes on arithmetic and accounting for merchandise, a romance of Tristan, list of spices, astronomical and astrological information, prayers, recipes, and poems.

On the other hand, the persistence of "intensive" reading after the printing revolution is well represented by the emergence of the novel in eighteenth century. Die Leiden des jungen Werthers (The Sorrows of Young Werther), an epistolary and lightly autobiographical novel by Johann Wolfgang von Goethe, first published in 1774, is a good example of a secular work that engrossed its readers in the manner of a religious text. It is well known that this novel started the phenomenon the "reading mania", a sentimental or emphatic form of reading based on emotional and individual responses (Wittmann 295). The reading of chivalric romances in the Middle Ages and Renaissance already triggered the imitation of the fictional action in real life. Dante describes a famous example in the episode of Paolo and Francesca in Canto V of the Inferno. The two lovers were stimulated to kiss each other by reading in a chivalric romance the fictional kiss between Guinevere, the wife of King Arthur, and the knight Lancelot. Cervantes created the character of Don Quixote who reads so many chivalric romances that he loses his sanity, decides to set out to revive chivalry and bring justice to the world. Nonetheless, the first form of mass imitation induced by reading novels was known as the Werther-Fieber (Werther-Fever), which conditioned young men throughout Europe to

\footnotetext{
${ }^{1}$ A hypertextual critical edition of Boccaccio's Zibaldone Laurenziano (Pluteo XXIX.8) is available at http://rmcisadu.let.uniroma1.it/boccaccio/.

${ }^{2}$ A digitized collection of commonplace books is available in the Harvard Open Collections at http://ocp.hul.harvard.edu/reading/commonplace.html.
} 
dress in the clothing style described for Werther in the novel. The imitation went to the point of repeating Werther's suicide. An exemplary figure of this type of modern reader is Gian of Brughi, a minor character in Italo Calvino's The Baron in the Tree (1957), a novel set in the Enlightenment culture of eighteenth-century Europe. Gian of Brughi, a brigand who avidly reads novels, ends up being hanged while reading Henry Fielding's Jonathan Wild. His only concern at death is how the novel he is reading ends; he dies happy when, just before being hanged, he learns that Jonathan Wild at the end of Fielding's book is also hanged.

Still, one should note that, unlike events in the Middle Ages, in these modern cases the imitation of the literary models takes place in a new cultural context in which the authorial voice rises to importance. The modern reader does not accept the refusal of innovation behind the medieval compilations and commentaries, based on summaries and citations of classic authors, sectioned, re-arranged and commented upon. The printing revolution ushered in the modern idea of the author and the related concepts of originality and intellectual property, to which we are now very much attached. The large audience created by the printing revolution brought to the fore the paradoxical implications of making private thoughts public (Eisenstein 229-230).

The printing revolution coincided with the triumph of the bourgeoisie throughout Europe and the emergence of a public sphere distinct from the court and the Church. In the Enlightenment, books and reading acquired an "emancipatory function" in the public consciousness (Wittmann 287). Moreover, only in the eighteenth century did people recognize the capacity of printed matter to "completely penetrate the reader's subjective life" (Watt, 184). The evolution of reading into an "individual process independent of social class" was another significant change introduced in the eighteenth century. In general, the "unruly form" of reading conceived as "naïve, non-reflexive and undisciplined" was predominant in this century. This form of reading was performed aloud by the rural population and among the urban lower classes (Wittman 290). At the same time, the book became a cultural commodity, entered the capitalist market, and found new kinds of readers associated with new institutions such as the "lending library" and the "reading societies" (306). Libraries gained more and more importance starting from eighteenth century as places and networks of reading. However, the principal location for reading remained the private room and the bourgeois living space.

The eighteenth century did not forget some of the natural and agricultural implications related to the Mediterranean etymology of the word "page". As we saw earlier, the Latin origin of pagina evokes the agricultural practice of delimiting a rectangular space for cultivating the vineyard. The columns included in the volumina evoked the rows of the vineyard showing how much the practice of writing and reading was connected to the natural environment. Philosophical schools of antiquity praised very much the practice of reading in a natural setting, starting from the daily program of the Pythagorean school that included solitary walks to natural places which had to be appropriately quiet for the disciple to gain the inner serenity necessary to converse and study (Hadot $309 \mathrm{ff}$.). The reading mode in monasteries maintained the spiritual and contemplative meditation of ancient schools in the new Christian setting. Starting from twelfth century, the city 
became the privileged site for the book and this change, along with the transformation of the book from a symbolic to an instrumental object, provoked intense reactions. Bernard of Clairvaux (1090-1153) criticizes the use of books in cities, as a sort of profanation of the authentic spirit of reading which for him is not the intellectual inquiry but the contemplation of nature and the meditation of the sacred Word. For this reason Bernard contrasted the cities with the forests: Experto crede: aliquid amplius invenies in silvis, quam in libris" ("Trust in one experienced: you will learn more from the forests than from the books") (Bernard of Clairvaux 241-242; Alessio 104). This reaction to the reduction of books to commodities and instruments of a imaginary reality detached from natural and spiritual places - Petrarca himself would be another example of such a stance - is not limited to the Middle Ages, but accompanies the history of reading up to our digital time. ${ }^{3}$

Intensive forms of reading were cultivated in natural settings also in the eighteenth century by intellectuals looking for retreat from society. One can see here the contradictory role played by reading and the book in the age of printing. On the one hand, it became a massive support for social formation and public opinion; on the other, it offered an attractive means for the individual to escape the flattening, at times unreasonable demands of society (Wittman 311). The eighteenth-century Italian philosopher Giambattista Vico (1668-1744) still remembers the contemplative importance of the natural surrounding for reading. Among other things he traces an original fantastic etymology of reading back to nature, revising the etymology Cicero gives for legere and relegere (to collect words, to read again and carefully) as a quality proper to religious people: "those who carefully reviewed and so to speak retraced all the lore of ritual were called religious, from relegere (to retrace or re-read)" (Cicero II xxviii). From a different perspective, Vico points to lex as the sylvan rustic origins of lego, a word that had its beginning, he says, in the forests. Lex first meant 'collection of acorns', from which was derived ilex ('oak'), for the oak produces the acorns by which swine are drawn together. Lex, he continues, was next a collection of vegetables, from which the latter were called legumina . Later on, still before the invention of writing, lex pointed to a collection of citizens or the public parliament. Finally, Vico concludes, only at the end of the process, did lex come to mean collecting letters and legere, 'reading' (New Science par. 240).

Vico explains the beneficial relationship of readers to the natural environment in the passage in his autobiography in which he thanks the forests and the nature he was exposed to during the years 1686-1695, spent away from Naples in Vatolla, a small village in the Cilento, as instructor of the family Rocca: "he felt most grateful for those woods in which, guided by his good genius, he had followed the main course of his studies untroubled by sectarian prejudice; for in the city taste in letters changed every two

\footnotetext{
3 Petrarch is one of the poets most aware of the living agency of the natural environment in the human life and poetry. Two of his letters are exemplar in this respect. The first one was addressed in 1352 to Francesco of the Church of Holy Apostles, concerning his rustic and solitary life. See Familiares XIII , 8. The second letter, written in 1347 to Giovanni Colonna, recounts the failure of the multiple attempts to protect Petrarch's garden from the "nymphs", namely the winter storms and flood waters. See Epistola metrica III 4.
} 
or three years like styles in dress" (Autobiography 133). Beyond the rhetorical intention, which, as has been pointed out by many scholars, aims to create the myth of himself as a solitary thinker, we must recognize here an explicit appreciation of the value of the philosophical meditation in contact with the natural environment. This was a significant moment of Vico's life, as he himself emphasizes, defining Vatolla a beautiful and solitary site where he was restored to health and had all the leisure to study and lay the foundation of the New Science. Vico's reasoning is very similar to that of Henri David Thoreau who more than a century after will live for two years in the forests on the shores of Walden Pond to rediscover the essentials reasons of life and culture.

One could argue that life in the woods for Vico and Thoreau was not really an immersion in nature, but rather an opportunity to read the classics of different cultures. In this perspective, Vico represents an interesting case study of "rational reading" in eighteenth century that anticipates how a writer and philosopher would read literature in this century. In this rural setting, Vico rediscovered Virgil, Latin poetry, the classics of Italian literature including its three crowning achievements, Dante, Petrarca and Boccaccio, and, above all, Platonic philosophy. Vico was reading the texts from these writers three times, following this plan,

The first time to grasp each composition as a whole, the second to note the transition and the sequence of things, the third in greater detail to collect the fine turn of thought and expression, which he marked in the book themselves instead of copying them into a commonplace or phrase book. (Autobiography 120)

Vico was convinced that this practice of reading would lead him to make good use of the classics "as his needs recalled them to mind in their context" which for him "is the sole measure of effective thought and expression" (ib.). As one can see, for certain aspects Vico's approach to reading is still related to the Scholastic method of cognitive reading including three levels of analysis, littera, sensus, and sententia.

The reading program of Thoreau was also very wide and included the Latin and Greek classics, Dante, Shakespeare, the Bible and the sacred writings of other cultures, such as the Vedas. One may note that in reality both Vico and Thoreau returned more than once to their respective cities during the alleged isolation in the woods, and that both possessed a considerable library. All this is true, but this does not detract from the value and veracity of the claim common to both that not only the reading of the classics, but also the partial exposure to "natural simplicity" of the forest pushed, on the one hand, Vico to condemn the Cartesianism developed in Naples and, on the other, Thoreau to condemn the superficiality of the culture of Concord resulting from the lack of good books that would nurture the basic needs of spiritual life. Ultimately, staying in Vatolla for Vico and in Walden for Thoreau represented a limited episode in their respective lives, but at the same time the interval was significant in the formation of their thought. Ralph Waldo Emerson in his essay Circles epitomizes the important idea behind Vico's and Thoreau's practice of reading: 
Literature is a point outside of our hodiernal circle through which a new one may be described. The use of literature is to afford us a platform whence we may command a view of our present life, a purchase by which we may move it. We fill ourselves with ancient learning, install ourselves the best we can in Greek, in Punic, in Roman houses, only that we may wiselier see French, English and American houses and modes of living. In like manner we see literature best from the midst of wild nature, or from the din of affairs, or from a high religion. The field cannot be well seen from within the field. The astronomer must have his diameter of the earth's orbit as a base to find the parallax of any star.

\section{Lector in rete}

The third revolution in reading since the Middle Ages may be seen both as a continuation and evolution of techniques of reading already available in medieval and early modernity; and as an introduction of completely new ways of digital reading. We have already seen a couple of examples illustrating the first point: the book wheel as an anticipation of hypertext and multiple platforms of reading made available by digital technology in our times. The hypertextual dimension was also part of the commonplace books that not by chance are rehabilitated today in the digital environment. For instance, Hoem and Schwebs argue in a recent article in favor of a "digital commonplacing" using online services that allow annotating, tagging, and categorizing content. Extracting and remixing information in digital environments, as it happened in analogue commonplacing - they conclude- makes possible to re-contextualize existing material in original and often unforeseen ways. ${ }^{4}$ Moreover, early modern examples of hypertexts include the polyglot bibles and dictionaries. The Complutensian Polyglot Bible is the first printed polyglot copy of the entire Bible, initiated by Cardinal Francisco Jiménez de Cisneros (14361517) and published by Complutense University of Madrid. Each page consists of three parallel columns of text: Hebrew on the left column, the Latin Vulgate in the middle, and the Greek Septuagint on the left column. On each page of the Pentateuch, the Aramaic text and its own Latin translation are added at the bottom (Fig. 6). The Italian lexicographer Ambrogio Calepino (1440-1510), commonly known by the Latin form of his name, Calepinus, published in 1590 in Basle what may be considered a hypertext dictionary, a Latin dictionary which contains eleven languages: "Ambrosii Calepini dictionarium undecim linguarum: respondent autem latinis vocabulis hebraica, græca, gallica, italica, germanica, belgica, hispanica, polonica, ungarica, anglica" (Catholic Encyclopedia 1913).

In this context it is worthwhile to mention that early incunabula already conceived the use of certain multimedia elements, as shown by the first printed edition of Petrarca's Rerum vulgarium fragmenta (Canzoniere) published in Venice in 1470 by Vindelin de Spira. The copy from the Queriniana Library in Brescia (Inc. Queriniano G V 15) is a unique and marvelous edition of the $R v f$, including extensive illustrations that serve as elaborate visual glosses of fundamental natural and psychological motifs in the poems. The marginalia and handwritten glosses are another unique feature of this edition. The written

${ }^{4}$ Digital commonplacing. First Monday, [S.I.], jun. 2015. Available at:

<http://firstmonday.org/ojs/index.php/fm/article/view/5451/4647 
glosses and the illustrations are integrated and provide a remarkable and exceptional interpretation of the $R v f$ favoring the interplay between different layers of texts and images (Fig. 7). This example of "hypertext" confirms that after the printing revolution the poems maintain a central position within the page while the written and visual commentaries occupy the margins. As in earlier examples, this is significant because, before the printing age, in some medieval manuscripts like the XIV century Latin Manuscript of Aristotle's De anima (On the Soul) the text lost its centrality on the page and the commentary by Averroes became more important (Fig. 8). In this case the commentary occupied the central position, the text was inscribed in the exterior columns and looked like an illustration (Zali 69). ${ }^{5}$

Despite all these similarities, the third revolution in reading is introducing unprecedented changes in the ways we read texts. First of all, the new and most important role that computation plays in research is as an "enabler of access" to an audience potentially far larger than the one retrieving books from libraries. The availability of texts in digital format is not in itself making the difference, though. What is really important is the organization of the texts available in searchable databases, "with well-defined schema describing that organization and well-defined access protocols for searching the data" (Foster 18). This new organization and architecture of texts creates a new situation for the reader, one in which the books are not on the shelves and not conducive to topographical memory. The lector in rete, as we may call the new reader protagonist of the third revolution, is first of all seated before a monitor screen; he or she scrolls through a computerized file in a way that apparently resembles the ancient readers of volumen or roll. In reality, the likeness is deceptive, since the now vertical scroll contains all the logical arrangements of text introduced by the codex, including quite often the pagination and different kinds of indexing. At first sight reading on the screen introduces a relationship with the text that combines two forms of reading that were the result of the two different textual logics and writing supports, the manuscript and the printed text.

Upon deeper scrutiny, one has to realize that the written text becomes an ephemeral entity on the screen: it lasts the time of its representation. It loses its perennial relationship with its supporting materiality. This is why, notwithstanding the qualities inherited from the previous revolutions in reading, it is not possible to speak of a "pagescreen." The electronic page is the result of a series of various visual configurations and platforms that may include the visualizations of documents in a mosaic of small windows that the reader can now choose. Anne Zali speaks in this regard of a "texte nomade" (4647). Terje Hillesund invites us not to confuse the electronic text in general as described above with the e-book in which the text is related to and integrated with a specific device based on electronic paper, such as the "Amazon Kindle"; she identifies different typologies of reading. Whereas deep and continuous immersive reading is possible with books and to a certain degree with e-books, the digital environment provided by Web browsers and hypertext favors a multimodal and discontinuous kind of reading. ${ }^{6}$ Moreover, the recent technological changes have radically modified the relationship

\footnotetext{
${ }^{5}$ http://classes.bnf.fr/idrisi/pedago/culture/aristote.htm

6 Terje Hillesund, "Digital reading spaces: How expert readers handle books, the Web and electronic paper." First Monday, 15(4), 2010. http://firstmonday.org/article/view/2762/2504
} 
between reading and writing to the point that the reader may now be considered a coauthor. In fact, whereas from the appearance of the first incunabula the room for reader intervention was limited to the blank spaces in a page, in the new era opened by digital texts the reader may now intervene at any moment in the production of the text not only by annotating, copying, and indexing, but also by recomposing the texts in new ways different from the original (Cavallo, Chartier 26-28).

For these aspects we should note that the electronic transmission of texts somehow resembles the Scholastic compilationes that emerged in the twelfth-century universities as an open textual form not based on an authorial voice. The digital revolution radically refashions the entire system of identifying and handling texts that was in place since the print revolution, giving birth to what nowadays we call Digital Humanities conceived as "a global, trans-historical, and transmedia approach to knowledge and meaning-making" (Burdick vii). Douglas Engelbart has popularized the idea that the cultural change envisioned by the Digital Humanities is so deep that is producing a revolution "far more significant than the invention of writing or even of printing", to the point that it is now opening the possibility of "augmenting human intellect" through computer technology. ${ }^{7}$

In this new situation some scholars have started to believe that we are living in a moment "marking a fundamental shift in the perception of the core creative activities of being human, in which the values and knowledge of the humanities are seen as crucial for shaping every domain of culture and society" (Jockers 3). The new representation of writing on the screen modifies the material nature of works. The change involves both writing and reading. To write an electronic text dissolves the distinction among the activities of writing, publishing, and distributing operative until now; it introduces the need for new categories in the aesthetic realm, in the definition of authorship, readership, in the bibliographic description, and in the ways libraries are cataloguing the new textualities. Finally, to read in front of the computer is very different from reading a volume, a codex, or a book. In digital collections what matters is not the individual object, the book, but the architecture that governs the electronic files and databases and their system of retrieving information based on search engines, keywords, data mining, and modeling.

This change in the conceptualization of reading with a focus on understanding entire systems rather than individual components has been already implemented not only in the Humanities but also and above all across a variety of scientific disciplines, engineering, and medicine (Foster 15). It may be interpreted as the unifying principle of a radical change in perception in our digital age similar to the move from the linear style to the painterly style in Baroque art as studied by Heinrich Wölfflin (1864-1945), the Swiss art historian who was instrumental in the development of a methodology for the formal analysis in art history in the early 20th century. The change was not limited to painting but involved literature and all the art forms. The linear style is the consequence of a linear vision and sees in lines and silhouettes, it appears to be still related to an element of

\footnotetext{
${ }^{7}$ See the official site of the Douglas Engelbart institute: http://www.dougengelbart.org/and http://www.viralblog.com/trends-innovations/the-inventor-of-the-computer-mouse-is-no-more/
} 
physical grasping; in the linear style the eye is like a hand that feels along the body and reproduces a sense of touch.

By contrast, this analogical element is not present in the painterly vision that sees in masses and is not interested in the edges. The eye is not the only path of vision and "the primary element of the impression is things as patches" to the point that it does not matter if these patches speak as color or only as lights and darks. In other words, "linear vision sharply distinguishes from form to form, while the painterly eye on the other hand aims at the movement which passes over the sum of things" (Wölfflin 18-19). The analogy between Digital Humanities approach and the seventeenth-century change of perception may lead us to consider that the digital revolution, by privileging the attention toward big data over the individual works, militates against our awareness of literature as vehicle of great works that nurtured the human ear and soul for centuries, to favor a new interest into the literary as such, as an element in the patchwork of civilization that loses the specificity it had for centuries of human history.

The new scenario opened to the lector in rete by the new forms of digital collections of text and data mining has led some scholars to advance the possibility of "distant reading" as opposed to the traditional close reading. A prominent figure of this approach is Franco Moretti, the founder of the Stanford Literary Lab, who addresses literary problems using scientific means based on computational modeling, quantitative analysis, and hypothesistesting. Matthew Jockers, a colleague and collaborator of Moretti, calls this new approach to literature "macroanalysis," and sees it in some general ways akin to economics or, more specifically, to macroeconomics (3). In this perspective, understanding literature no longer implies studying particular texts, but aggregating and analyzing massive amounts of data. Moretti claims that "close reading can't uncover the true scope and nature of literature because the sample size used by traditional criticism is too small" (47ff). He proposes the quantitative approach to literature as "a more rational literary history" (Graphs, Maps, Trees 4). Moretti's scientific approach leads him to suggest that distant reading should replace close reading, not simply supplement it. Jockers is very clear about the substantial change in the notion of reading that is at the core of these digital humanities research methodologies. In fact, he prefers the term analysis over reading. The former term, associated with the prefix macro, "places the emphasis on the systematic examination of data, on the quantifiable methodology" and "deemphasizes the more interpretive act of reading." Significantly he concludes, "this is no longer reading that we are talking about - even if programmers have come to use the term "read" as a way of naming functions that load a text file into computer memory" (Jockers 25).

The macroanalysis oriented by digital humanities is noticeably different from the macrooriented traditional literary studies such as Ian Watt's impressive study The Rise of the Novel (1957) that ultimately remains a study of the novel based on an analysis of just a few authors. Jockers believes that the authors chosen by Watt as convenient touchstones for his history, "cannot be considered representative of the ten to twenty thousand novels that make up the period Watt attempts to cover" (25). In Jockers' perspective the quantitative approach would allow computer to help us see more and deeper, to go beyond what we are capable of reading as solitary scholars. The underlying assumption is 
that by exploring an unprecedented scale of literary records, "we will better understand the context in which individual texts exist and thereby better understand those individual texts" (27).

Similarly, Moretti is convinced that studying literary periods and genres by means of a close study of "representative" texts is not an adequate interpretative methodology because it stitches together separate bits of knowledge about individual cases when the final result of the research shouldn't be a sum of individual cases but "a collective system, that should be grasped as a whole" (Graphs, Maps, Trees 4). On the other hand, Jockers sees all the limitations of data mining and reminds that the goal of big data and digital macroanalysis is not to provide irrefutable conclusions about what a text might mean but more modestly "an alternative method for accessing texts and simply another way of harvesting facts from and around texts" (29). In this perspective macroanalysis is a methodology that might complement the seemingly antithetical idea of close reading.

The enhancement of human perception aided by information technology is particularly evident in a geographic information system (GIS) that makes possible to store, search, and analyze historical data in a geographical context. One good example is the Electronic Cultural Atlas Initiative (ECAI) is one among many projects created by the Pacific Language Mapping edited by David Blundell. The ECAI claims that mapping these languages and cultures is important because it allows geographically viewing layers of data through time. This process also permits geo-referenced data to be accessible with the ability to electronically connect, display, share, and analyze materials. ${ }^{8}$ Franco Moretti theorizes the use of maps for literary and sociologial studies. He holds that literary maps are a good way to prepare a text for analysis. The text has to be reduced to a few discrete elements extracted from the narrative flow; those elements will then be visualized in a map or a series of maps that eventually will possess qualities that were not visible at the lower level (Graphs, Maps, Trees 53). The discrete element that Moretti extracted from Mary Mitford's Our Village - a collection of village stories published in five volumes between 1824 and 1832 - are the walks of the characters in the stories. This element is apparent to all the readers of Our village; however, the maps of these walks reveals something that no reader had noticed before, namely the "circular pattern they project on the English countryside". The map in itself is not an explanation, but it provides a model of the narrative universe that brings some hidden pattern to the surface for the reflection of the reader who in the end, thanks to a complex and comparative mapping of the texts, becomes able to discern broader and deeper layers of meaning, such as how "the various directions in which rural class struggle, the industrial take-off, and the process of state formation 'have converted' the shape of nineteenth-century idylls" (64; Fig. 9).

However, it is not completely clear to what extent distant reading represents an improvement in our way of understanding individual texts. It certainly adds important statistical and visual aids to the reading of multiple texts. On the other hand, the impression one gets from Moretti's graphs and maps is that of a mass of data treated as magnifying glasses to approach an enormous number of literary texts. It recalls Wölfflin's idea of Baroque vision as characterized by a movement from the absolute

8 http://ecai.org/austronesiaweb/PacificLanguages.htm 
clearness of the Renaissance to a relative clearness that nevertheless reveals new layers of meaning. In the new vision certain "difficulties" are placed in the way of perception, to improve and deepen it: the image becomes complex and "the spectator, for whom the simple has become too transparent, finds an interest in the solution of more complicated problem" (Wölfflin 196).

For example, in Tintoretto's Pietà a shadow falls over Christ's face which, while it deemphasizes the plastic values, strengthens the viewer's impression of suffering by highlighting a part of the forehead and a part of the lower face ( $\underline{\text { Fig. 10 }})$. For the Baroque, the old display of forms striving to mold every shape into an even clearness became unnatural, unworthy to repeat. Hence the importance of marginal details and ornaments that acquired a new structural value. One can see that something like that is happening in the opposition of distant reading to close reading. The paradox of distant reading is similar to the paradox of Baroque vision: in the end its shows the clearness of the unclear. As the seventeenth century found beauty in form being swallowed by darkness, so does the distant reading find intellectual inspiration in massive data that obscure the aesthetic value of literary works to reveal new and more complex layers of meaning in texts that supposedly have lost their appeal to traditional and linear forms of reading.

This new attitude of the lector in rete is well represented by Irnerio, one of the minor characters in Italo Calvino's If on a Winter Night a Traveler. His position on reading is the following:

"Me? I don't read books!" Irnerio says.

"What do you read, then?"

"Nothing. I've become so accustomed to not reading that I don't even read what appears before my eyes. It's not easy: they teach us to read as children, and for the rest of our lives we remain the slaves of all the written stuff they fling in front of us. I may have had to make some effort myself, at first, to learn not to read, but now it comes quite naturally to me. The secret is not refusing to look at the written words. On the contrary, you must look at them, intensely, until they disappear." (84)

There is a paradox here. The way in which Irnerio and more in general the lector in rete do not read books is actually another form of reading based on viewing. Irnerio lives in a world that is completely written and made of images and audiovisual media; in this world books and texts are not important for their solid and concrete physical presence, they become an ephemeral reality that disappears in the moment in which we look at them.

\section{Reading and viewing}

In what we consider the most culturally advanced parts of the world, the United States and Europe, we witness on the one hand the twilight of the canon of Western written culture, and on the other hand phenomena of deculturation, the decline of the so-called "strong readers" reading many books per year. The new situation is characterized also by 
the emergence of a new mode of mass reading that appears to be in many ways anarchical, egotistical, and egocentric (Petrucci, Reading to Read 358-360). The publishing industries' creation of a mass book market is obliterating every rational criterion of book selection. Exemplary in this regard is the case of what happened in Eastern Europe after 1989. In East Germany, for example, the mass of strong readers that before that date was used to read the classics and Marxist authors are now devouring "whatever the West Germany book market offers in the way of Trivialliteratur, hobby books, mysteries, science fiction, travel books, etc". The result have been disastrous, famous publishing houses are closing, the writers association has dissolved, and the first book dump has been created in the environs of Leipzig (357).

The new condition was first instigated by the consumerist orientation of the publishing industries and somehow later reinforced by the emergence of the instantly available, electronic book. It is illustrated among other things by the end of the traditional order of reading. The new reader is more and more often in front of the screen of a mobile device, avoiding what once were considered good and ordered practices, in favor of free and relaxed modes of reading (363). These deep changes have been taking place for decades. Somehow they precede the digital revolution and essentially depend on the emergence of not alphabetic ways of seeing and reading based on the iconic, multisensory, convivial and entertaining culture introduced by television. The emergence of this "visual culture" started first with cinema as theorized by Béla Balázs in his Visible Man, or the Culture of Film (1924), where he claims that the discovery of printing and written culture in general have gradually rendered the human face and body illegible, introducing a dematerialized, abstract and over intellectualized culture. In this way, he writes, "the visible spirit was transformed into a legible spirit, and a visual culture was changed into a conceptual one"; for Balázs the erasure of the visible spirit and the alienation of the human body that started with the confusions of tongues in the Tower of Babel was about to be overcome by the art of film, the "first international language" based on human gestures (9-10).

This new vision is just the opposite of what for centuries has been the alphabetic vision, performed in sequential reading through the decoding of the written signs bearing a phonic value. Starting in the 1940s, the analogical images purveyed by television have played an even bigger part than cinema in promoting this new orientation towards the word. Furthermore, since the 1990s cyber culture has disseminated the digital image as a further disembodiment and virtualization of reality. As a result, audio-visual media are increasingly replacing books and reading as vehicles of mass information and education. We may again see a historical anticipation of this process in Baroque culture that introduced a new way of thinking through images and attributed a moral and didactic value to them, as Cesare Ripa, for example, did in his Iconologia (1593). In audio-visual media, reading is not important; what really matters are listening and viewing. A reader and a viewer have different attitudes towards learning and approaching the world. Viewing in the new media is for the most part outward-looking and requires less effort than reading as it promises an immediate, intuitive access to our object of attention and inquiry; this access is based on images and the visual areas of our brain that for our ancestors were responsible for object recognition. 
As a consequence, in our time knowledge is increasingly pursued through listening and viewing; in other words, through non-alphabetic and simultaneous forms of intelligence. The authority of the "reality" created by television, as the word tele itself indicates, is the result of a distant vision in which multiple places and distances converge. As Giovanni Sartori writes, it is the cognitive authority of the image that overwhelms our sensory experience of the world since the eyes believe in what they see: we naturally believe that "what one sees is real and therefore true" (13). Significantly, all the abstract and intellectual filters made possible by the alphabetic vision and reading words are reduced if not neglected when one "reads" images. As a result, in our visual culture we tend to believe that what is not visible is not real or true. These profound changes are reconfiguring our perceptions and mental structure; some scholars like Sartori speak of the end of homo sapiens with his analytical and sequential approach to reality, in favor of the emergence of the homo videns more and more unable to respond to the stimuli of the written words and surrendering to an unthoughtful, simultaneous, and multisensory apprehension of the world.

Cyberspace and the internet have created the possibility of reuniting in one single dimension all the images that once were tied to distinct and independent media, from artworks to cinema and television. The power of images in our culture has now been further magnified by the ubiquity of computer screens and the various possibilities of augmented reality by computer-generated sensory input such as sound, video, graphics or GPS data. The digital image, conceived more and more not in terms of representation of reality but as simulation obtained through an interactive visualization, has become more independent from possible real referents. The images invading our lives may be preserved in digital archives and are easy to access without having to move away from our desktop or the laptop. Moreover, they can be simply edited and manipulated by the viewer through ad hoc software.

Todd Gitlin speaks of the overwhelming saturation of stimuli produced by the torrent of images and sounds created by the unlimited use of media. It is not by chance that these changes coincide with the worldwide persistence of high percentages of non-literacy. We are now witnessing in some quarters the phenomenon of a return to illiteracy due to the reduction or absence of reading and writing. ${ }^{9}$ Certainly, the spread of literacy today meets strong impediments that are not only political or sociological: at the base of the difficulties in the spread of literacy is a new way of looking at the world and a new order of the senses. In this situation, some critics like Veronica Neri lament the low quality of the images provided by the internet and, more generally, the need for an ethical and

\footnotetext{
${ }^{9}$ According to the Unesco Institute for Statistics today 781 million adults worldwide still cannot read or write - two-thirds of them (496 million) are women.

(http://www.uis.unesco.org/literacy/Pages/literacy-data-release-2014.aspx). Developed nations are also facing a growing illiteracy problem. As for the Usa, the 2004 report of the National Endowment for the Arts To Read or not to Read shows "a general decline in reading among teenage and adult Americans. Most alarming, both reading ability and the habit of regular reading have greatly declined among college graduates. These negative trends have more than literary importance" (Dana Gioia 3). The report connects the declines with evident social, economic, cultural, and civic implications.
} 
responsible approach to the images in the web lest we be swallowed up by them (Neri 82, 113).

We are coming to realize how the hypericonic culture in which we live and the attendant reduction of authentic space of reading are producing a cognitive shift that is changing the consistency of society. As Caleb Crain writes,

If one person decides to watch "The Sopranos" rather than to read Leonardo Sciascia's novella "To Each His Own," the culture goes on largely as before -both viewer and reader are entertaining themselves while learning something about the Mafia in the bargain. But if, over time, many people choose television over books, then a nation's conversation with itself is likely to change. (134)

Crain points to the importance of television in triggering the cognitive shift we are witnessing; more recently other writers and scholars, like Nicholas Carr, have not shied away from arguing that paying more attention to the internet is responsible for the big shift, which they tend to see only in negative terms. For some sociologists authentic reading is today returning to its original restricted social base, a "self-perpetuating minority", and it is not clear at this point whether the reading minority will have in the future "the power and prestige associated with an increasingly rare form of cultural capital or will be viewed as the eccentric practitioners of an increasingly arcane hobby" (Griswold, McDonnel and Wright 138).

In his article "Is Google Making Us Stupid?" and more extensively in his book The Shallows: What the Internet Is Doing to Our Brains, Carr argues that computer searching, multitasking, social networking and videogaming are making us more superficial. In this perspective, Naomi S. Baron holds that the Internet is promoting a new a notion of reading that structurally privileges "locating information over deciphering and analyzing more-complex text" ("Redefining Reading 200). In her recent book Baron admits the advantages of eReading (search the text, promotion of extensive reading, democratization of the access to the written word) but emphasizes the drawbacks: in her view eReading and digital reading in general are more apt for short pieces or for light content, and not appropriate for longer more serious works that require rereading and analyzing; moreover, she argues that reading onscreen modifies the nature of reading by transforming it from and individual encounter with a text and an author into a social experience as it happens for example in online reading groups like Goodreads or the Reading Group Center created by Facebook (Words Onscreen xii-xv; 208 ff.).

On the other hand, Marian Wolf suggests the opportunity and necessity to preserve the best of both worlds, the print and digital literacies. She argues that is possible and essential to encourage deep reading online; the internet may provide us with new ways of teaching and encouraging students and readers in general to be purposeful, critical, and analytical about the texts they encounter. In other words, hypertexts may not be only a source of distraction, as one-sided critics of digital reading claim. Hypertexts may also provide important tasks and tools to facilitate successful reading online and the development of a genuine digital literacy oriented by critical thinking. Wolf presents as 
an example the CAST Universal Design Learning edition for young readers of Edgar Allan Poe's "The Tell-Tale Heart", that includes tutoring on how to use a specific reading strategy (such as visualizing, summarizing, predicting, or questioning) to better understand a passage. Nonetheless, she argues that the pursuit of deep reading through digital media should not lead to neglect "the formation of the deep-reading processes in the medium of human's first literacy." She recalls the fascinating precedents in the history of writing: "The Sumerian writing system, in use 3,000 years ago, was preserved alongside the Akkadian system for many centuries. Along the way, Akkadian writing gradually incorporated, and in so doing preserved, much of what was most valuable about the Sumerian system" (Wolf, The Importance of Deep reading).

Without negating the importance of both print and digital literacy, Katherine Hayles insists on the shift in cognitive styles as a consequence of the increased presence of networked and programmable media in our lives. She articulates the shift as a contrast between deep attention and what she calls "hyper attention":

Deep attention, the cognitive style traditionally associated with the humanities, is characterized by concentrating on a single object for long periods (say, a novel by Dickens), ignoring outside stimuli while so engaged, preferring a single information stream, and having a high tolerance for long focus times. Hyper attention is characterized by switching focus rapidly among different tasks, preferring multiple information streams, seeking a high level of stimulation, and having a low tolerance for boredom. (187)

The cognitive shift toward hyper attention characterizes above all the younger generation of the digital natives, who show worrying tendencies, particularly in the case of video gamers. The hyper attention devoted to the overwhelming stimuli provided by different media produces what in an older terminology was known as attention deficit disorder (ADD); significantly, this term has now been replaced by the newer diagnostic terminology of "attention deficit hyperactivity disorder" (ADHD). Hayles argues that children growing up in media-rich environments literally have brains wired differently as the plasticity of human brain and the brain's synaptic connections are coevolving with an environment in which media consumption is a dominant factor. However, she continues, media stimulation, if structured appropriately, may contribute to a positive synergistic combination of hyper and deep attention that may be applied in higher education (192193). In this perspective, for Hayles it is possible to draw positive pedagogical implications from the cognitive skills involved in video-gaming as for gamers what really counts is not simply the fun of playing but the opportunities offered by the games for achievement, freedom, and, in some instances, connections to other players. In other words, she concludes, "stimulation works best when it is associated with feelings of autonomy, competence, and relatedness" (195).

The ideal situation for this possible synergy is the interactive electronic classroom that provides a wireless laptop for each student and many screens of different format on the wall to provide the opportunity to practice new pedagogical models based on active learning and interactions among students and the teacher. In these classrooms moments 
of deep attention and reading alternate with sequences of hyper attention that favor multitasking and the use of the so called Google jokeys: participants in a presentation or class who surfs the Internet for resources mentioned by the presenter. These are then displayed simultaneously with the presentation, helping to clarify the main topic being presented. Hayles argues that the capacity for deep attention may and should be enhanced by the use of hyper attention. In this regards she suggests that to encourage digital natives to engage with more traditional objects of study, the teacher may start by using popular web sites that trade on hyper attention and activity. For instance, she studied with her students the strategies of self-presentation used in the extremely popular Facebook as an introduction to the "sly and subversive" self-presentations in The Education of Henry Adams (196). To conclude, while the lector in rete appears to be well suited above all for hyper attention, immediate information processing, multi-tasking, and media-driven cognitive approaches, he or she needs to find ways for preserving the irreplaceable value of deep reading still characterized by more time-consuming cognitive processes that are vital for a thoughtful and reflective life. Nevertheless, a large portion of scientific research is nowadays directed to push back the brain's speed barrier, and read with greater speed and efficiency. The team at the Laboratory for Visual Learning - a collaboration of scientists from University of Massachussets Boston, MIT, and Harvard, that includes Marc Pomplun, Chen Chen, and Matthew H. Schneps - represents a significant example of this direction.

\section{This issue of Humanist Studies \& the Digital Age}

The present issue of Humanist Studies \& the Digital Age contributes to the debate on varieties of reading and attention. On the one hand it confirms the features of reading in our time as described in the historical and theoretical overview delineated above; on the other hand, it introduces new hopes for the possible positive effects of digital innovation in the Humanities by documenting inventive academic projects in which the typical hyper attention required by the digital environment is combined with cognitive strategies oriented toward deep reading. The ideal reader these projects have in mind is surely a hyper reader who has to come to terms with multiple layers of meaning in the text, as prompted by the hyper- and intertextual setting in which the reading takes place.

In his brief videoconference, "Change of Paradigm: From Individual to CommunityBased Scholarship," Massimo Riva clarifies that the digital revolution involves not only the transformation of the procedures of scholarly research and learning but also and more importantly the transformation of its goals. The scholarly work is being increasingly made over into a collective, collaborative, large-scale enterprise characterized by the move from discursive to graphic-algorithmic forms of data presentation and interpretation. He holds that as humanists engaged with a potentially radical transformation of the community we belong to, our most daunting task is how to transpose established scholarly practices onto the new platform, envisioning new goals and outputs for our traditional tasks.

Riva is the Editor in Chief and Coordinator of The Pico Project, an electronic edition and commentary online (in Latin, English and Italian) of Giovanni Pico della 
Mirandola's Oratio De Hominis Dignitate and Conclusiones Nongenta. In his blog Experiments in Scholarsourcing, he discusses the reading procedures particularly suited for the Pico Project. Dino Buzzetti's intervention on the blog suggests the application of "topic modeling" techniques as a way of detecting sources of the Conclusiones CM in the available digitized corpora of some medieval authors (Albertus Magnus, Thomas Aquinas and possibly John Duns Scotus). This procedure, usually associated with distant reading can be of help in identifying possible sources of a given text. On the other hand, the application of topic modeling as envisioned by Buzzetti may be brought to bear also on the practice of Linked Open Data annotation, a procedure more commonly associated with close reading. Ernesto Priani's and Ana María Guzman Olmos' article 'From fragment to hypertext: Adding layers of reading" published in this issue of Humanist Studies \& the Digital Age, further illustrates that the hypertextual representation of the Pico della Mirandola's texts allows visualizing different temporal layers of reading. The term "layers of reading" is a metaphor to explain how, historically, each successive reading of a text creates a new layer, an independent "stratum of meaning," superimposed on the previous one. The authors of the article believe that digital editions and the digital reading have the potential to create a philosophical methodology, based on the awareness of the historical construction of each layer of reading.

Two articles discuss the issue of intertextuality, close and distant reading in digital contexts, and the advantages of a hypertexual approach to reading. "Digital Readers of Allusive Texts: Ovidian Intertextuality in the Commedia and the Digital Concordance on Intertextual Dante" by Julie Van Peteghem introduces the notion of a digital concordance as a reading and research tool to explore intertextual passages online, and illustrates how a digital concordance of highly allusive texts can change how we read and research such texts. Van Peteghem developed a project on Digital Dante in collaboration with the Center for Digital Research and Scholarship at Columbia University, which in the first phase highlights the Ovidian intertextuality in Dante's Divina Commedia. Since the intertextual passages in the Commedia require a reading not restricted to the obviously corresponding verses, but attentive to the broader textual contexts, Van Peteghem shows how the digital concordance on Intertextual Dante greatly facilitates such a contextualized and deep reading. The visualization of the corresponding passages (side by side, highlighted within context) and the search options (by category of text reuse or by canto/book/poem) further the study of (Ovidian) intertextuality in the Commedia, as illustrated in the article with examples from the site.

"From Quill to Mouse: Digitizing the 'Woman of Letters' 1861-1922, by Cristina Gragnani and Ombretta Frau describes a project in Italian Digital Women's Studies, Invisiblewomen.org ${ }^{10}$ which is currently being developed as a collaboration between Mount Holyoke College and Temple University. This project provides an interpretive, thematic website on the material culture of Italian female intellectuals between 1861 and 1922. Gragnani and Frau envision In-visiblewomen.org as a tool that allows the investigation of women's agency in promoting social change and the interconnections between women writers' material culture, their private space, their access to the public sphere, and the impact of the new media revolution on women's social status. The two

${ }^{10}$ At time of publication, the website's URL was not yet available. 
authors hold that the web site will provide a multi-layered, interpretive platform stemming from the expert contribution of scholars in the field. This project has a remarkable visual component as well: the interface is based on a commissioned oil painting representing a late nineteenth century woman writer's virtual study. Each object in this ideal study (pen, ink bottle, letters, magazines etc.) will be clickable and will lead to an encyclopedia-type entry. Through the painting, users will be able to access two searchable databases organized hierarchically and interconnected through tagging: a themes database, and an authors database.

The last two articles are related to the use of the hypertext Oregon Petrarch Open Book (OPOB) as a reading and research tool for a seminar taught at the University of Oregon in Winter 2014. "Re-reading Petrarca in the Digital Era" by Massimo Lollini and Pierpaolo Spagnolo, presents the use of digital encoding as a device for close reading of individual poems as well as a foundation for a distant reading of Petrarca's masterpiece. The encoding of Petrarca's masterpiece performed in the seminar was based on keywords meant to identify a network of different themes (Poet, Laura, Metaphysics Nature Metamorphoses and Urban Culture) in the Rerum vulgarium fragmenta. These themes were considered as interrelated and interdependent. The poet himself becomes the sphere in which all the topics combine in their specific connotations. However, this sphere is related to, dependent on and intersected by the other four spheres. The encoding measured the different manifestations, levels, and meanings of the intersecting relationships. The study of the visual interpretation of the $R v f$ in the Inc. Queriniano G V 15 paralleled the close reading and encoding activity, and helped students to develop a visual rendering of their themes and a pointed and original and creative interpretation of Petrarca's masterpiece.

Finally, "E-Philology and Twitterature" by Massimo Lollini and Rebecca Rosenberg presents an original use of Twitter to interpret and rewrite the poems of Francesco Petrarca's $R v f$ implemented within the OPOB. This activity was partially inspired by the idea of Twitterature developed by Alexander Aciman and Emmett Rensin. Like them, the authors of the article believe that our digital era should develop new and more functional ways of addressing literary texts, but at the same time they are convinced that what Aciman and Rensin call the "burdensome duty of hours spent reading" cannot be eliminated. On the contrary, the new ways of reading in the digital era as they envisage them are the result and consequence of broader and deeper reading activities. The OPOB conceived the project of writing 366 tweets, out of the 366 poems that make up the last version of Petrarca's $R v f$, as the result of different philological activities, from reading the texts in the original language to consulting manuscripts, translations and intersemiotic renderings of the texts. The reading activities that brought to the writing of the 366 tweets are reminiscent of the medieval Scholastic method as they were not exclusively aimed at a simple comprehension of the literal meaning (littera) of the poems. This was just the first stage performed through the reading of the original text and the writing of the paraphrase. The writing of the summary conceived as the general meaning (sensus) of the poem represented the second stage. Finally, the individuation of the keywords and the writing of the tweet allowed reaching the full profundity of the poem in a sort of 
proposition (sententia). The reader will find the actual 366 tweets from the $R v f$ both in Italian and English in the Appendix to the article.

\section{Works cited}

Alessio, Franco. "Conservazone e Modelli del Sapere nel Medioevo." Rossi, Pietro. La Memoria Del Sapere : Forme Di Conservazione E Strutture Organizzative Dall'antichità a Oggi. Bari: Laterza, 1988. 99-133. Print.

Bible. Polyglot. Alcalà de Henares: Arnao Guillén de Brocar, 1514-1517. Print.

Balázs, Béla, Erica Carter, and Béla Balázs. Béla Balázs: Early Film Theory : Visible Man and the Spirit of Film. New York: Berghahn Books, 2010. Print.

Baron, Naomi S. Words Onscreen: The Fate of Reading in a Digital World. New York, NY: Oxford University Press, 2015. Print.

---. "Redefining Reading: The Impact of Digital Communication Media." PMLA Modern Language Association, 1(128), 193-200. Print.

Bernard of Clairvaux. Epistola 106. Patrologia latina vol. 182. 241-242. Web source available at http://patristica.net/latina/\#t182 Date accessed: 03 Aug. 2015.

Buonaventure, Saint. "Commentarium in I Librum Sententiarum.” Opera Omnia. Ad Claras Aquas, I, 1882. Print.

Burdick, Anne, et al. Digital Humanities. Cambridge, Mass: MIT Press, 2012. Internet resource. Print.

Calvino, Italo, and William Weaver. If on a Winter's Night a Traveller. London: Vintage, 1998. Print.

Carr, Nicholas. The Shallows: What the Internet Is Doing to Our Brains. New York, NY: W.W. Norton \& Company, 2010. Print.

Catholic Encyclopedia (1913)/Ambrogio Calepino. Wikisource . Wikisource, 20 Apr. 2013. Web. 13 Aug. 2015

Cavallo, Guglielmo, Chartier, Roger, and Cochrane, Lydia G. A History of Reading in the West. Amherst: U of Massachusetts, 1999. Print.

---. Cavallo, Guglielmo, Chartier, Roger. "Introduction.” Cavallo, Guglielmo., Chartier, Roger, and Cochrane, Lydia G. A History of Reading in the West. 1-36. Print. 
Cicero, Marcus T, and H Rackham. De Natura Deorum: Academica. London: W. Heinemann, Ltd, 1933. Print.

Crain, Caleb. "Twilight of the Books." The New Yorker 24 Dec. 2007: 134. Academic OneFile. Web. 23 March. 2015. Print.

Dane, Joseph A. The Myth of Print Culture: Essays on Evidence, Textuality, and Bibliographical Method. Toronto: University of Toronto Press, 2003. Print.

Dickinson, Emily, and Thomas H. Johnson. The Complete Poems of Emily Dickinson. Boston : Little, Brown and Company, 1960. Print.

Eisenstein, Elizabeth L. The Printing Press As an Agent of Change: Communications and Cultural Transformations in Early Modern Europe. Cambridge [England]: Cambridge University Press, 1979. Print.

Emerson, Ralph Waldo. Essays and English Traits. Vol. V. The Harvard Classics. New York: P.F. Collier \& Son, 1909-14; Web source available at Bartleby.com, 2001. www.bartleby.com/5/ Date accessed: 30 July, 2015.

Gitlin, Todd. Media Unlimited: How the Torrent of Images and Sounds Overwhelms Our Lives. New York: Metropolitan Books, 2001. Print.

Gioia, Dana. "Preface." To Read or Not to Read: A Question of National Consequence: Executive Summary. Washington, DC: National Endowment for the Arts, 2007. Web source. Date accessed: 30 August, 2015.

Griswold, Wendy, Terry McDonnell, and Nathan Wright. "Readers and Reading in the Twenty- First Century." Annual Review of Sociology 31 (2005): 127-41. Print.

Hayles, N K. "Hyper and Deep Attention: the Generational Divide in Cognitive Modes." Profession. 2007.1 (2007): 187-199. Print.

Hillesund, Terje. "Digital reading spaces: How expert readers handle books, the Web and electronic paper." First Monday, 15(4), 2010. Web source available at http://firstmonday.org/article/view/2762/2504 (ver. 04.04.2015). Date accessed: 3 July, 2015.

Hadot, Pierre. Qu'est-ce Que La Philosophie Antique? Paris: Gallimard, 1995. Print.

Hoem, Jon; Schwebs, Ture. "Digital commonplacing.” First Monday, [S.1.], Jun. 2015. ISSN 13960466. Web source available at: <http://firstmonday.org/ojs/index.php/fm/article/view/5451/4647>. Date accessed: 03 Aug. 2015. doi:10.5210/fm.v20i7.5451. 
Hugo de Sancto Victore [Hugh of Saint Victor]. Didascalicon de studio legendi.

IntraText Digital Library, 2007. Web source available at

<http://www.intratext.com/IXT/LAT0506/>.

Date accessed: 10 June 2015.

Illich, Ivan. In the Vineyard of the Text. Chicago and London: Chicago UP, 1993. Print.

Jockers, Matthew L, and Jockers, Matthew Lee. Topics in the Digital Humanities :

Macroanalysis : Digital Methods and Literary History. Urbana, IL, USA: U of Illinois,

2013. Topics in the Digital Humanities. Web source. Date accessed: 10 August 2015.

Moretti, Franco. Distant Reading. 2013. London: Verso; 2013. Print.

---. Graphs, Maps, Trees: Abstract Models for a Literary History. London and New

York: Verso, 2005. Print.

Neri, Veronica. L'immagine Nel Web: Etica E Ontologia. Roma: Carocci, 2013. Print.

Petrarca, Francesco. Familiares XIII , 8. Francesco Petrarca, and Aldo S.

Bernardo. Letters on familiar matters $=$ Rerum familiarium libri. New York: Italica Press, 2005. 204-206. Print.

---. Epistola metrica III, 4. Francesco Petrarca, and Ferdinando Neri. Rime, trionfi, e poesie latine. Milano: R. Ricciardi, 1951. 772-776. Print.

Petrucci, Armando and Charles M. Radding. Writers and Readers in Medieval Italy, trans. New Haven: Yale UP: 1995. Print.

Petrucci, Armando. "Reading to Read: A Future for Reading." Cavallo, Guglielmo, Chartier, Roger, and Cochrane, Lydia G. A History of Reading in the West. 345-367. Print.

Ramelli, Agostino. Diverse et artificiose machine. Parigi : In casa del'autore, co[n] priuilegio del Re, 1588. Beinecke Rare Book and Manuscript Library, Yale University. Print.

Ripa, Cesare, and George Richardson. Iconology. New York: Garland Pub, 1979. Print.

Sartori, Giovanni. Homo Videns: Televisione E Post-Pensiero. Roma: Laterza, 1997. Print.

Matthew H. Schneps. "Using Technology to Break the Speed Barrier of Reading." Scientific American. Scientific American, a division of Nature America, Inc. Sep 8, 2015. Web source available at http://www.scientificamerican.com/article/using-technology-tobreak-the-speed-barrier-of-reading/?WT.mc_id=SA_WR_20150909.. Date accessed: 09/15/2015. 
Watt, Ian. The Rise of the Novel. Harmondsworth: Penguin, 1957. Print.

Wittmann, Reinhard. "Was there a Reading Revolution at the End of he Eighteenth Century?" Cavallo, Guglielmo, Chartier, Roger, and Cochrane, Lydia G. A History of Reading in the West. 285-312. Print.

Wölfflin, Heinrich. Principles of Art History. The Problem of the Development of Style in Later Art. New York: Dover Publications, 1950. Print.

Wolf, Maryanne, and Catherine J. Stoodley. Proust and the Squid: The Story and Science of the Reading Brain. New York, NY: HarperCollins, 2007. Print.

---. Wolf, M., \& Barzillai, M. (2009). “The importance of deep reading.” Educational Leadership, 66(6), 32-37. Web. Accessed 09-11-2015. 


\section{Appendix}

\section{Figures quoted in the text}

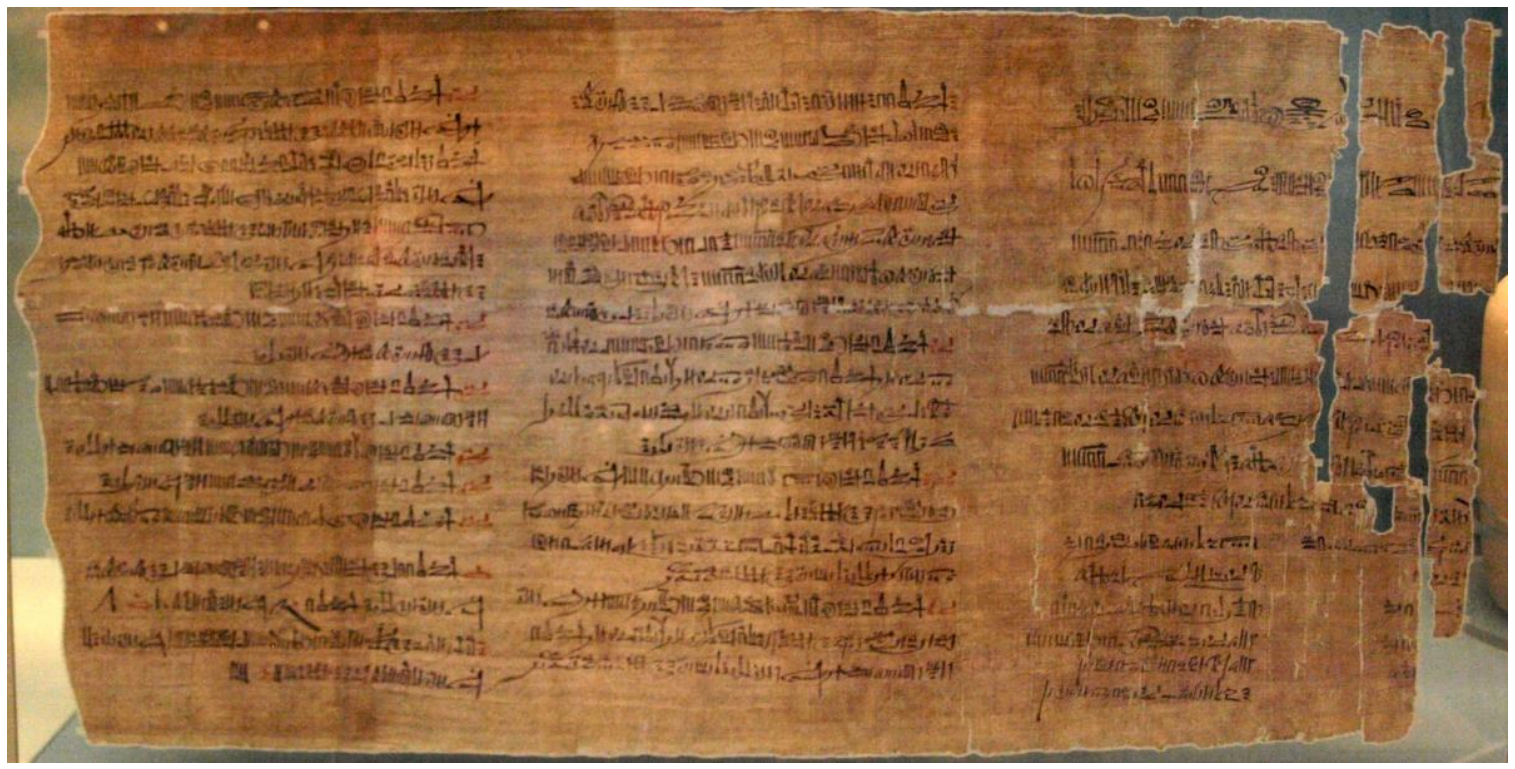

Figure 1: Abbott Papyrus, a record written in hieratic script; it describes an inspection of royal tombs in the Theban Necropolis and is dated to the 16th regnal year of Ramesses IX, ca. 1110 BCE. Multi-license with GFDL and Creative Commons CC-BY-SA-2.5 and older versions (2.0 and 1.0). Back to pag. 2

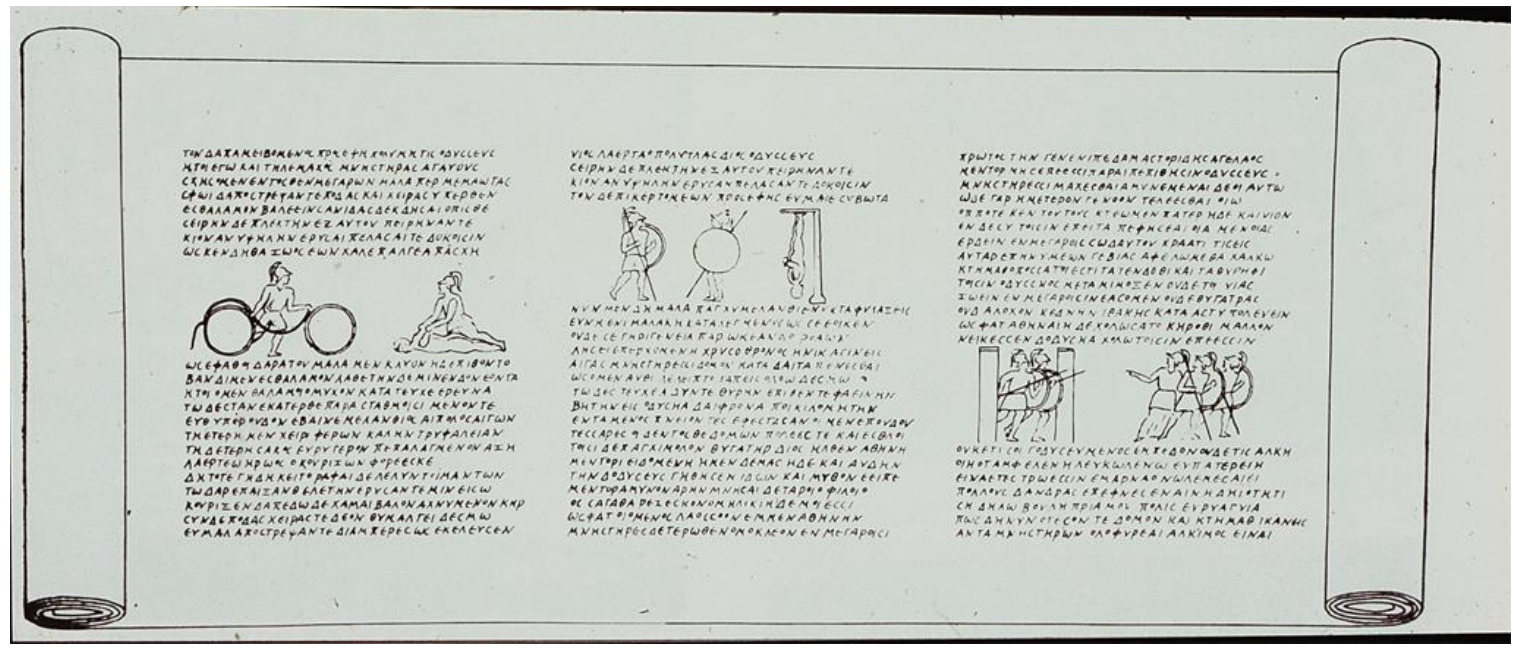

Figure 2: Vatican Virgil Vat. lat. 3225 Reconstruction: an illustrated Odyssey volumen from the 3rd C. BC, late 4th-early 5th $\mathrm{C}$. Data fron University of California San Diego. Back to pag. 2 


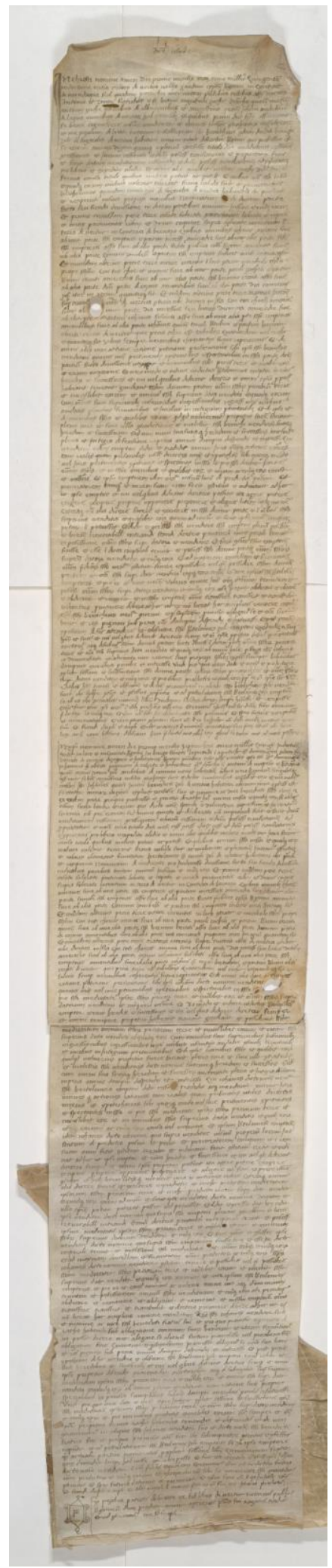

Figure 3: Three vellum pieces sewn together to make a roll. Parchment - 1455 x 175 mm from Pavia, Italy. Language: Latin. Source: Bancroft Library UC Berkeley. Back to pag. 2 


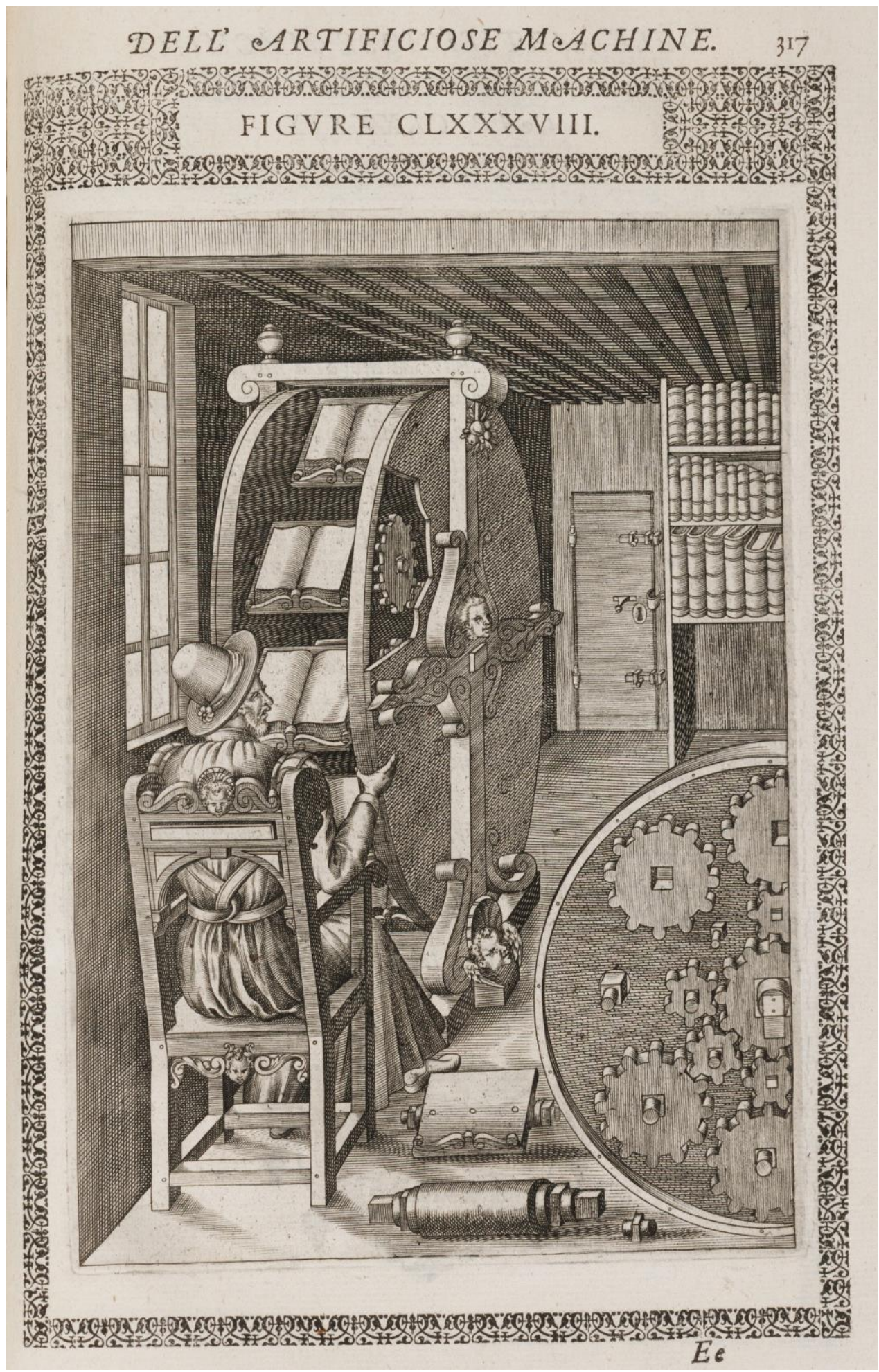

Figure 4 Agostino Ramelli's Ruota dei libri

Source: Beinecke Rare Book \& Manuscript Library (Yale University)

\section{Back to pag.5}




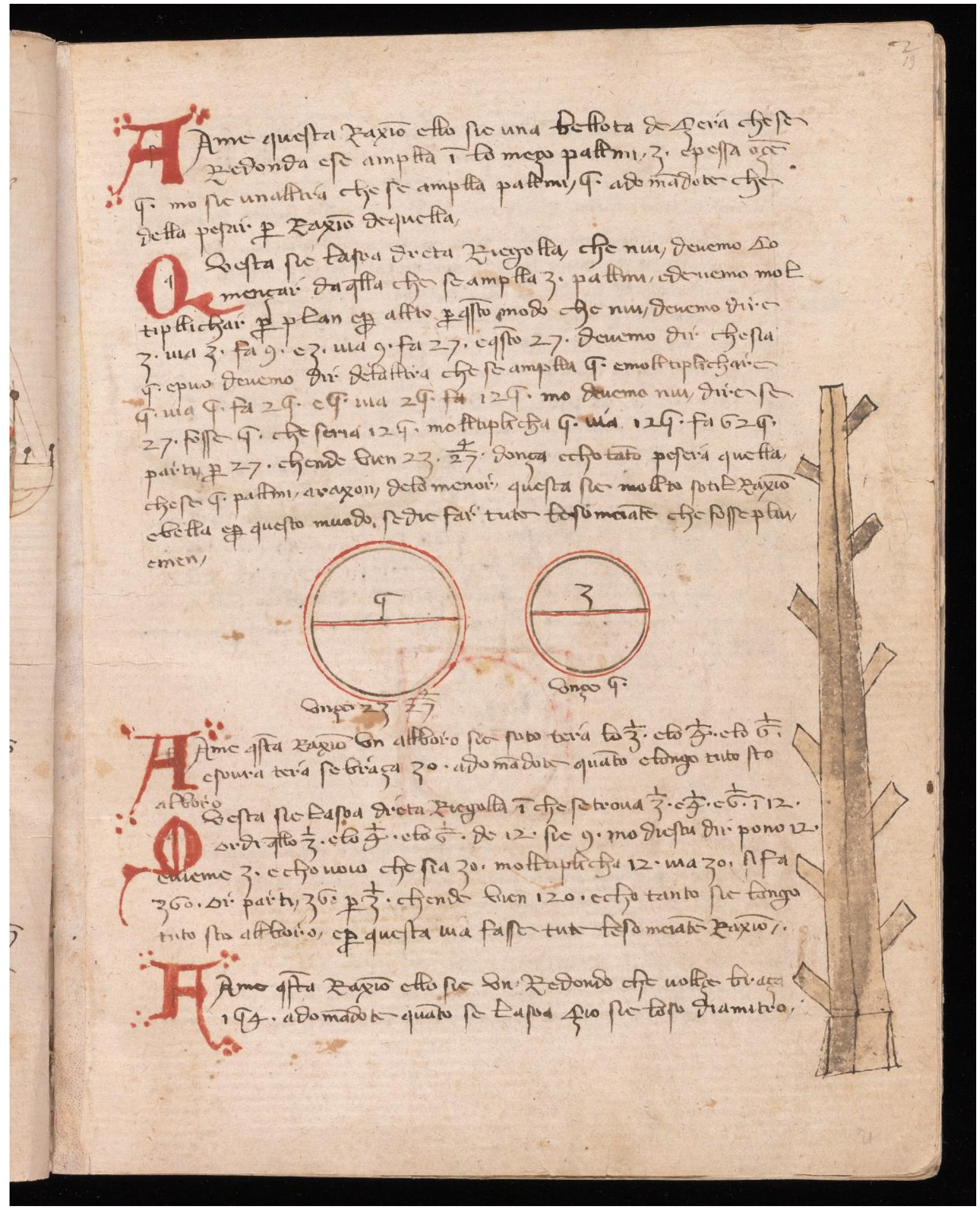

Figure 5: Merchant Commonplace book.

Source: Beinecke Rare Book \& Manuscript Library (MS 327), Yale University)

Back to pag. 5 


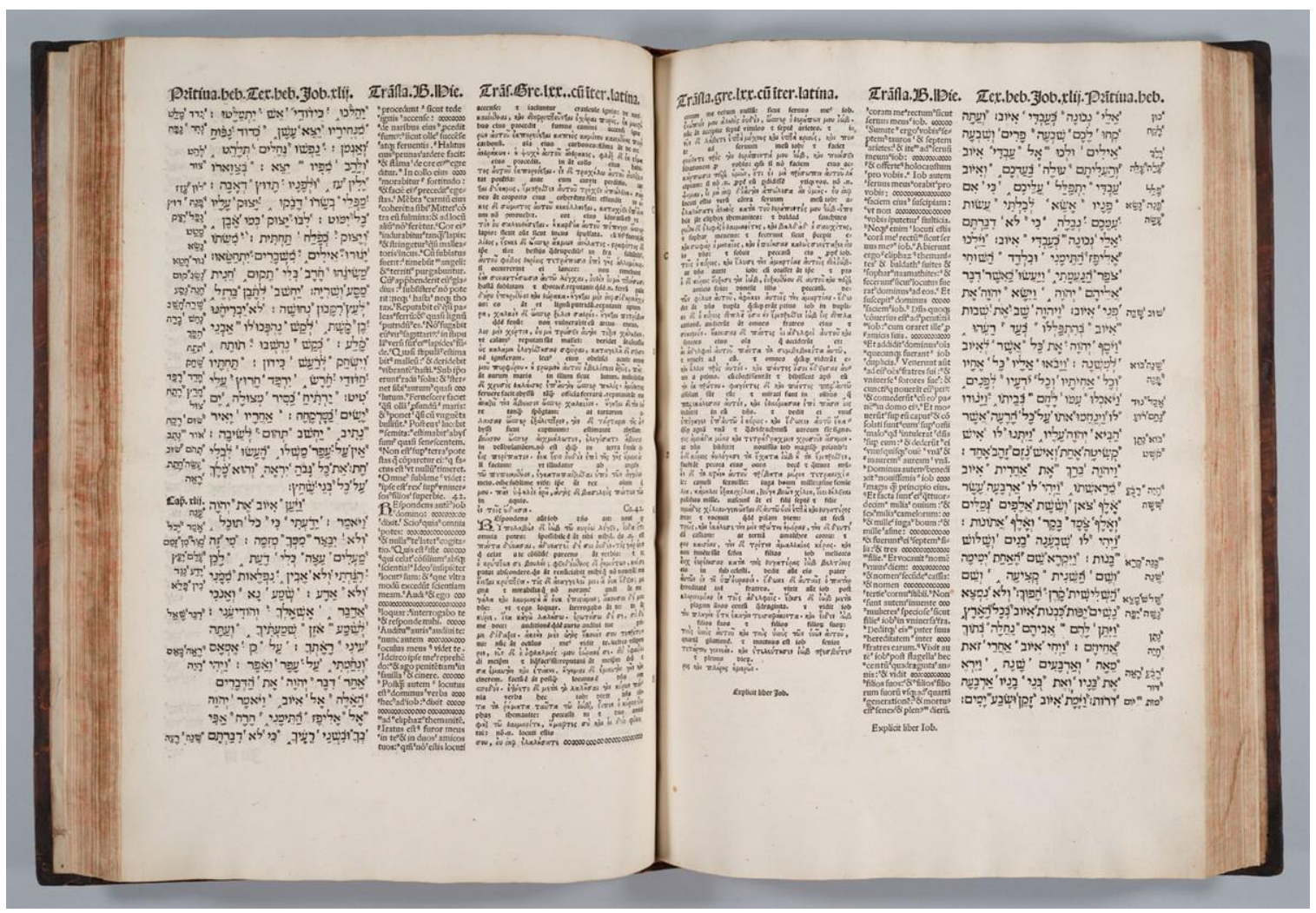

Figure 6: Bible. Polyglot. Alcalà de Henares: Arnao Guillén de Brocar, 1514-1517. Source: http://www.sothebys.com/en/auctions/ecatalogue/2014/music-continentalbooks-manuscripts-l14402/lot.21.html Back to pag.10 


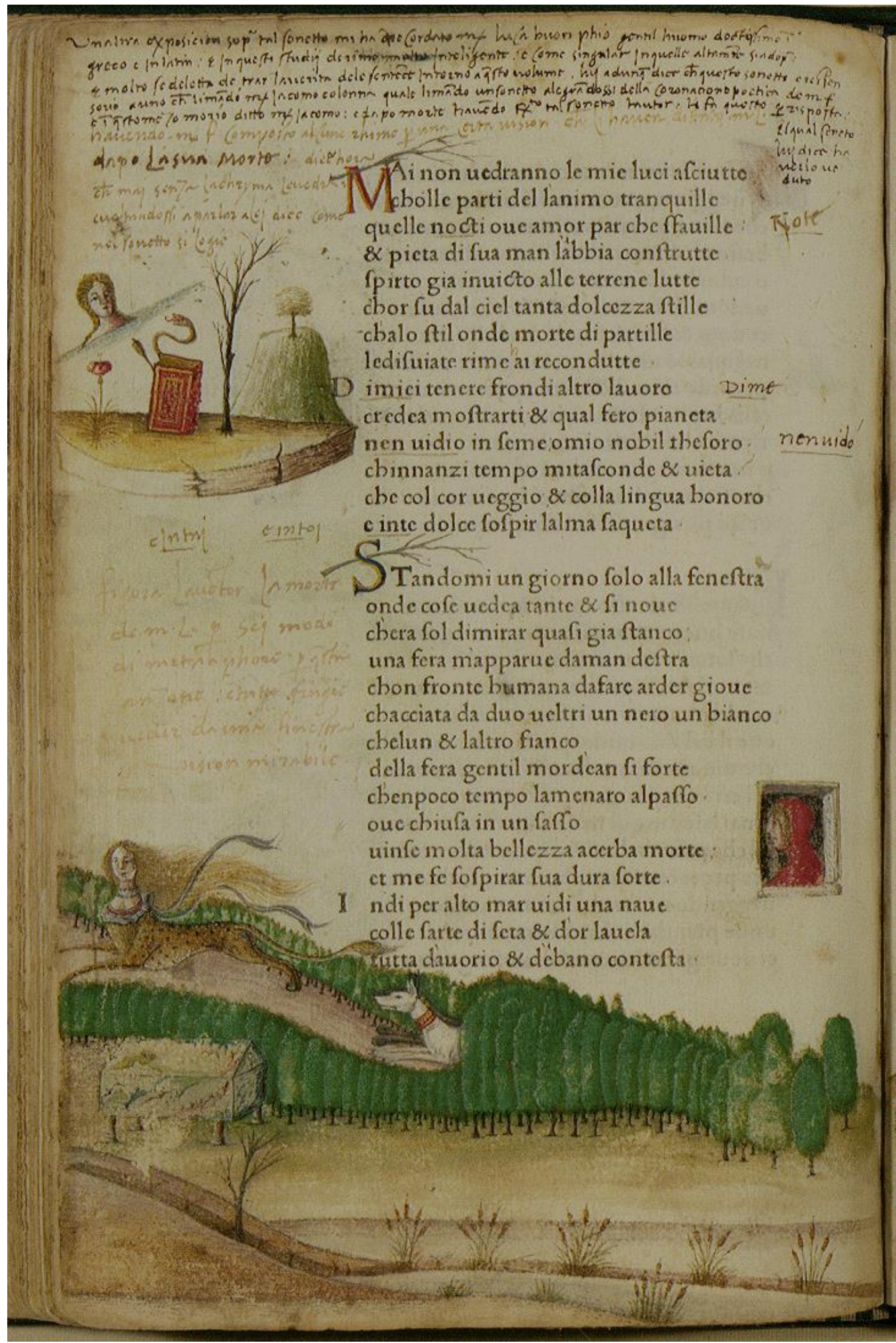

Figure 7: Francesco Petrarca, Canzoniere. I Trionfi. Venezia: Vindelino da Spira, 1470. Source: Queriniana Library, Brescia (Inc. Queriniano G V 15). University of Oregon Digital Collection. Back to pag.10 


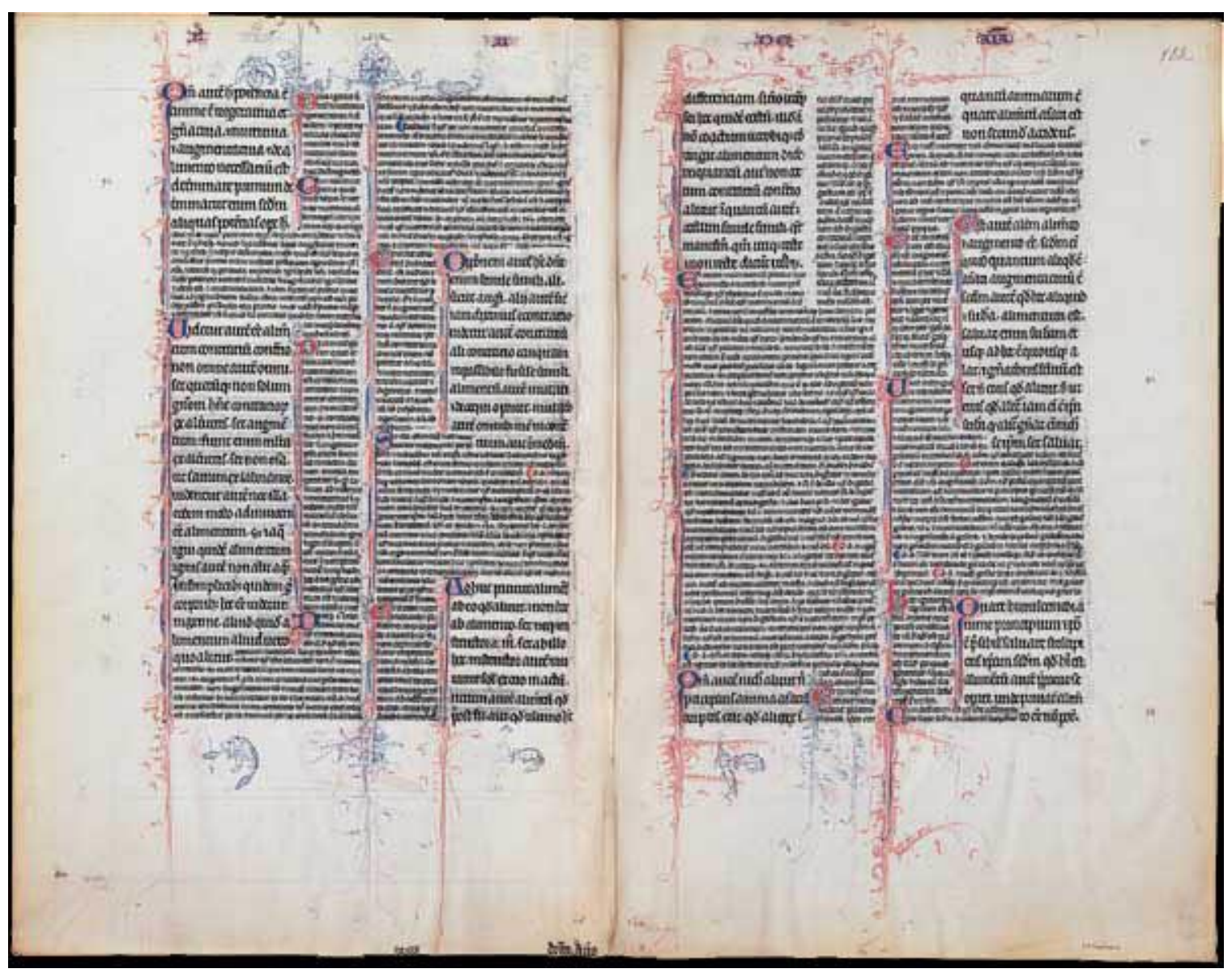

Figure 8: Aristotle, De anima, Lain translation with the commentary by Averroes. Parchement, Paris, beginning of XIV century.e. BnF, Manuscrits (Latin 17155 fol. 181v-182)

Source: http://classes.bnf.fr/idrisi/pedago/culture/aristote.htm

\section{Back to pag.10}


FIGURE I4: Mary Mitford, location of stories in volumes I, III, V

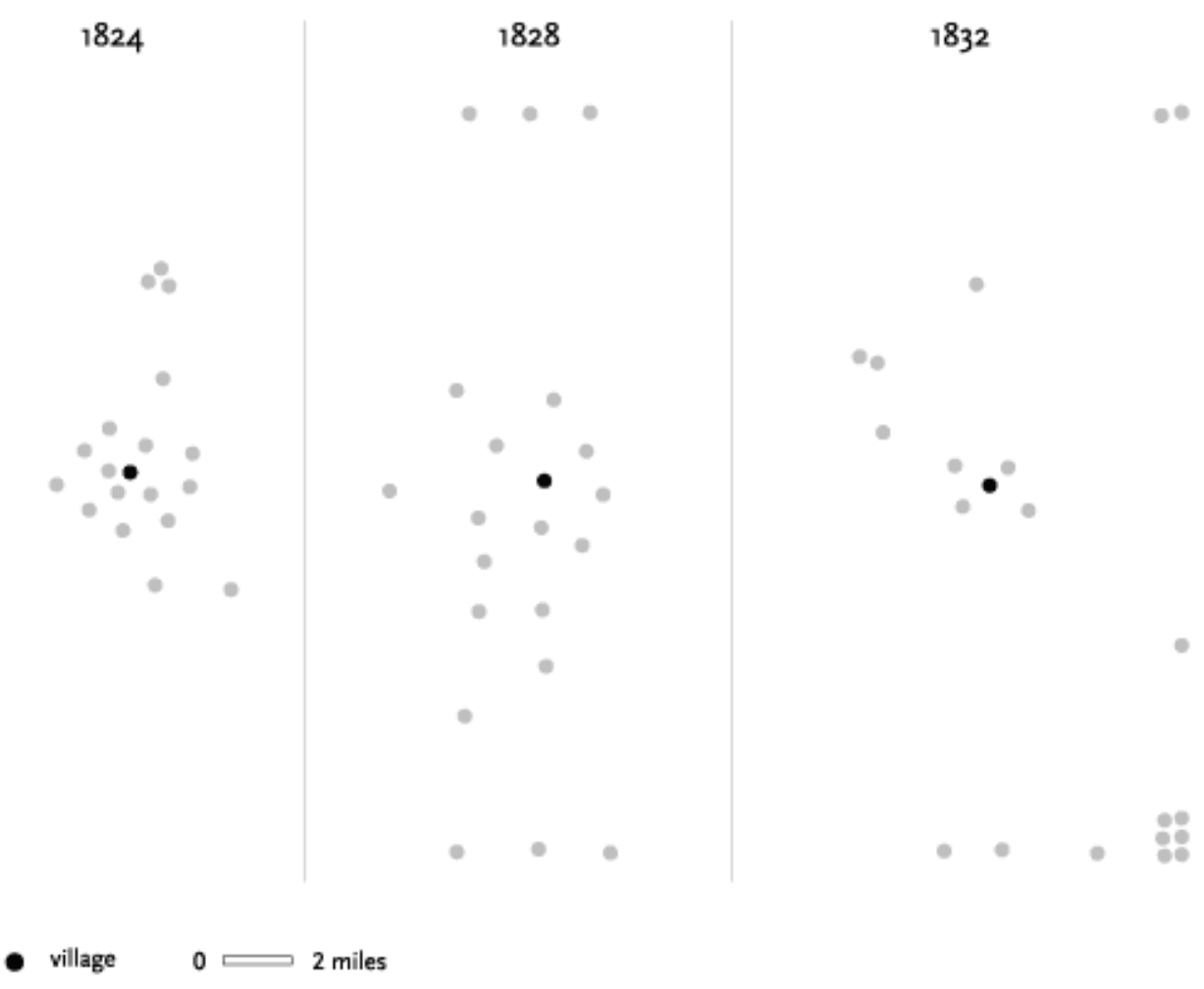

In a very large part of morphology, our essential task lies in the comparison of related forms rather than in the precise definition of each; and the deformation of a complicated figure may be a phenomenon easy of comprehension, though the figure itself have to be left unanalysed and undefined... The essential condition is, that the form of the entire structure under investigation should be found to vary in a more or less uniform manner.

D'Arcy Thompson, On Growth and Form

Figure 9: Franco Moretti, Graphs, Maps, Trees, p.61. Originally published in New Left Review, 26 March-April 2004, 101. Back to pag. 14 


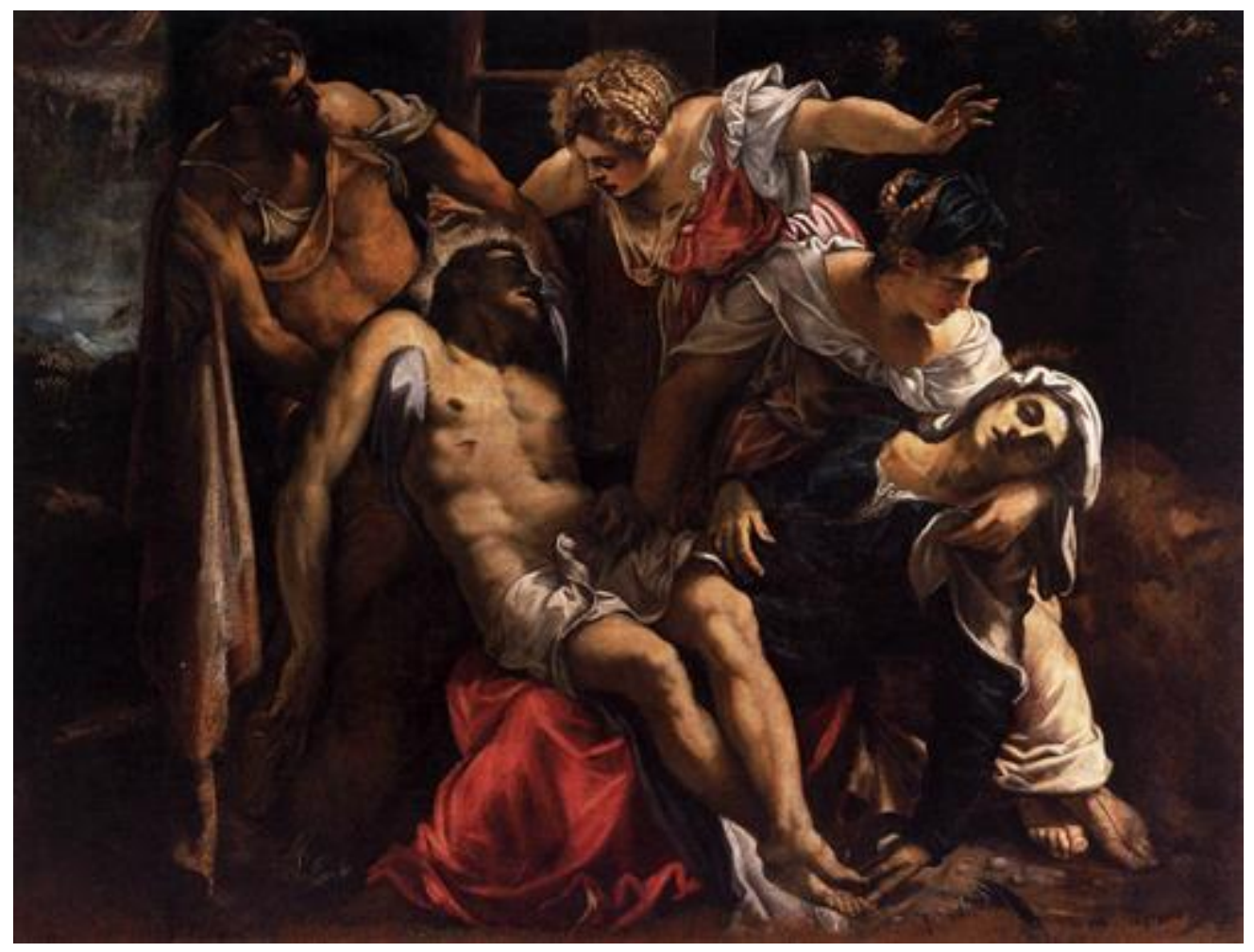

Figure 10: Tintoretto, Pietà (1560ca). Gallerie dell'Accademia, Venice, Italy. Source: http://www.wga.hu/frames-e.html?/html/t/tintoret/index.html Back to pag. 14 